\title{
Strong Association Between Weight Reduction and Suppression of Cardiovascular Events in Recent Clinical Trials of DPP4 Inhibitors, GLP-1 Receptor Agonists, and SGLT2 Inhibitors
}

\author{
Tatsuo Yanagawa
}

The 2008 US Food and Drug Administration (FDA) regulation requires to demonstrate in clinical trials of new antidiabetic drugs, that these drugs do not increase the risk of development of cardiovascular events as compared to existing drugs, after adjustment for major risk factors. It has been difficult to show superiority of newer drugs after adjustments for the major risk factors, and in fact, superiority could not be demonstrated in the initial three trials of DPP-4 inhibitors [1-3]. Therefore, it came as an unexpected surprise that the SGLT2 inhibitor empagliflozin showed superiority in the EMPA-REG OUTCOME study [4]. Thereafter, superiority was again demonstrated in one study of SGLT2 inhibitor, CANVAS [5], two studies of GLP-1 receptor agonists, LEADER [6], and SUSTAIN-6 [7], but not in another two studies of GLP-1 receptor agonists, ELIXA [8], and EXCEL [9].

Various hypotheses have been proposed in regard to factors influencing the demonstration of superiority, but there is no widely accepted theory. It has been suggested that differences in the patients' background characteristics may be a factor. It is also possible that the incidence of cardiovascular events is not sufficiently high in studies with a short study period, and that there is a bias towards patients with slightly higher risk being in the active drug group.

We focused on weight reduction, because weight gain is a risk factor for cardiovascular diseases, independent of disordered glucose metabolism, elevated blood pressure, and abnormal lipid profile [10]. We examined the correlations between the body weight changes and hazard ratios before and after treatment in eight studies [1-2, 4-9]. In SUSTAIN-6 [7], since the analysis was carried out with semaglutide $0.5 \mathrm{mg}$ and $1 \mathrm{mg}$ treatment respectively, both were adopted. The TECOS study [3] was excluded, as there were no data on the body weight changes in this study.

As shown in the Figure 1 [1-9], there was a strong cor-

Manuscript submitted August 24, 2018, accepted August 28, 2018

Department of Medicine, Nerima General Hospital and Institute of Healthcare Quality Improvement, Public Interest Incorporated Foundation Tokyo Healthcare Foundation, 1-24-1 Asahigaoka, Nerima-Ku, Tokyo 176-8530, Japan. Email: tyana-mj@xj9.so-net.ne.jp

doi: https://doi.org/10.14740/jocmr3587w relation between weight reduction and reduction in the hazard ratio in all trials $\left(\mathrm{R}^{2}=0.88, \mathrm{~F}=51.6, \mathrm{P}=1.8 \times 10^{-4}, \mathrm{n}=9\right)$. These results suggest that novel antidiabetic drugs that decrease the body weight also suppress cardiovascular events. It should be noted in interpreting this result that these trials were performed on patients at higher risk of cardiovascular events, such as patients with relatively advanced disease, elderly patients, and patients with some degree of renal impairment. Therefore, patients with low cardiovascular risks may have different results.

Weight reduction results in various metabolic improvements, through reduction in the visceral fat area. It has been reported that liraglutide and SGLT2 inhibitors reduce the visceral fat area, which has been shown to be associated with cardiovascular diseases [11].

\section{Grant Support}

None.

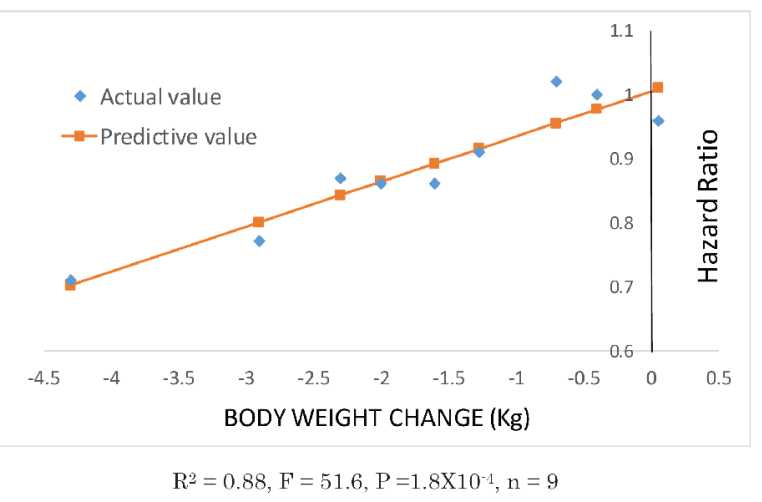

Figure 1. Correlations between weight changes and hazard ratios in eight clinical studies. Data plotted with diamonds were obtained from the relevant literature. Data on the body weight changes in the EMPAREG OUTCOME study were obtained from the figure in the supplementary data and estimated as being a mean of $-2 \mathrm{~kg}$. From left to right: SUSTAIN-6, semaglutide $1 \mathrm{mg}$; SUSTAIN-6, semaglutide $0.5 \mathrm{mg}$ [7]; LEADER [6]; EMPA-REG OUTCOME [4]; CANVAS [5]; EXCEL [9]; ELIXA [8]; SAVOR-TIMI53 [1] and EXAMINE [2]. The TECOS study [3] was excluded, as there were no data on the body weight changes. 


\section{Conflict of Interest}

I have no conflict of interest and there is no source of funding.

\section{References}

1. Scirica BM, Bhatt DL, Braunwald E, Steg PG, Davidson J, Hirshberg B, Ohman P, et al. Saxagliptin and cardiovascular outcomes in patients with type 2 diabetes mellitus. N Engl J Med. 2013;369(14):1317-1326.

2. White WB, Cannon CP, Heller SR, Nissen SE, Bergenstal RM, Bakris GL, Perez AT, et al. Alogliptin after acute coronary syndrome in patients with type 2 diabetes. N Engl J Med. 2013;369(14):1327-1335.

3. Green JB, Bethel MA, Armstrong PW, Buse JB, Engel SS, Garg J, Josse R, et al. Effect of sitagliptin on cardiovascular outcomes in type 2 diabetes. N Engl J Med. 2015;373(3):232-242.

4. Zinman B, Wanner C, Lachin JM, Fitchett D, Bluhmki E, Hantel S, Mattheus M, et al. Empagliflozin, cardiovascular outcomes, and mortality in type 2 diabetes. N Engl J Med. 2015;373(22):2117-2128.

5. Neal B, Perkovic V, Mahaffey KW, de Zeeuw D, Fulcher G, Erondu N, Shaw W, et al. Canagliflozin and cardiovascular and renal events in type 2 diabetes. N Engl J Med. 2017;377(7):644-657.
6. Marso SP, Daniels GH, Brown-Frandsen K, Kristensen P, Mann JF, Nauck MA, Nissen SE, et al. Liraglutide and cardiovascular outcomes in type 2 diabetes. N Engl J Med. 2016;375(4):311-322.

7. Marso SP, Bain SC, Consoli A, Eliaschewitz FG, Jodar E, Leiter LA, Lingvay I, et al. Semaglutide and cardiovascular outcomes in patients with type 2 diabetes. N Engl J Med. 2016;375(19):1834-1844.

8. Pfeffer MA, Claggett B, Diaz R, Dickstein K, Gerstein HC, Kober LV, Lawson FC, et al. Lixisenatide in patients with type 2 diabetes and acute coronary syndrome. N Engl J Med. 2015;373(23):2247-2257.

9. Holman RR, Bethel MA, Mentz RJ, Thompson VP, Lokhnygina Y, Buse JB, Chan JC, et al. Effects of once-weekly exenatide on cardiovascular outcomes in type 2 diabetes. N Engl J Med. 2017;377(13):1228-1239.

10. Global Burden of Metabolic Risk Factors for Chronic Diseases Collaboration, Lu Y, Hajifathalian K, Ezzati M, Woodward M, Rimm EB, Danaei G. Metabolic mediators of the effects of body-mass index, overweight, and obesity on coronary heart disease and stroke: a pooled analysis of 97 prospective cohorts with 1.8 million participants. Lancet. 2014;383(9921):970-983.

11. Mathieu P, Boulanger MC, Despres JP. Ectopic visceral fat: a clinical and molecular perspective on the cardiometabolic risk. Rev Endocr Metab Disord. 2014;15(4):289298. 